\section{The thesis that won't go away}

SIR-I sympathize greatly with Beverly Halstead's position on PhD theses (Nature 331, 497; 1988) and almost entirely disagree with the conclusions.

For one thing, experience on a higher degrees committee has taught me that requirements of different subjects are very different, and it is possible that detailed requirements for one subject will not suit another, even when these subjects are closely related.

The general principles, of course, remain the same. These are to demonstrate that the student knows how to initiate, undertake and complete a piece of research and how to present it, evaluate its significance, propose further development and continuation and how to profit from negative results obtained in the course of the work.

To finish a thesis in a reasonable length of time - and in chemistry three years from the first degree is quite enough - it may be necessary to relax the requirement for completion of a piece of work; and in this case adequate discussion of negative results is more than necessary to show the author has profited from them.

I do not agree that theses are never referred to again after examination. In my experience it is not usually difficult to obtain photocopies, and again in chemistry, these often contain experimental the work.

Applied Chemistry

University of Natal,

King George $V$ Avenue,

Durban 4001, South Africa details missing in publication which may be very important in repeating or extending

Department of Chemistry \&

$$
\text { D. A. H. TAYI.OR }
$$

SIR-Although I am not familiar with the details of the individual case reported and personally experienced by Beverley Halstead in which an established scientist with a distinguished research record was denied a PhD degree, in the extract from the external examiner's report there is clear evidence that the work as submitted by the candidate was taken seriously; and I understand that he was also given the opportunity to decline the MPhil. degree and try again with an enlarged standardtype version of the original thesis. In other words, according to the examiner's report, it would have been perfectly acceptable if the published text were directly incorporated into the thesis, which is something that not all universities allow. To me the external examiner's point of view does not seem unreasonable. In fact, if I were in his position and if my role in the process was reduced to listening to some verbal comments on work which

\section{Radiocarbon-dating the shroud}

SIR-Dr M.S. Tite (Nature 332, 482; 1988) has revealed the new procedures decreed by Cardinal Ballestrero, Archbishop of Turin, for radiocarbon-dating the Shroud of Turin. These differ so remarkably from those of the original protocol agreed by all parties at the Turin Workshop held in the fall of 1986 and chaired by Professor Carlos Chagas, president of the Pontifical Academy of Sciences [H.E. Gove, Nucl. Instr. Meth. Phys. Res. B29, 193 (1987)], that a brief comparison of the two seems in order.

1. The involvement of seven laboratories has been reduced to three. This eliminates the possibility of detecting a mistake made in the measurement by one or more of the three laboratories. As Tite knows, such mistakes are not unusual.

2. The use of both decay counting and accelerator mass spectrometry (AMS) has been changed to AMS only. The two methods are distinct and independent.

3. The amount of cloth each AMS laboratory receives has been increased by almost a factor of two. With this much material, several more laboratories could have been included.

4. Representatives of the three laboratories will not be permitted to observe the sample removal from the shroud. Tite will be the only independent scientist present at this operation.

5. The shroud and control samples will not be unravelled and thus, despite Tite's comments to the contrary, the shroud sample will be much more easily identifiable.

6 . The scientific body connected with the Roman Catholic church which has a high reputation in the world of science, the Pontifical Academy of Sciences, has unaccountably been excluded from official participation in any aspect of this important and controversial radiocarbon measurement.

7. The acknowledged textile expert selected at the Turin Workshop to remove the shroud sample has been replaced by some unnamed person.

All these unnecessary and unexplained changes unilaterally dictated by the Archbishop of Turin will produce an age for the Turin Shroud which will be vastly less credible than that which could have been obtained if the original Turin Workshop protocol had been followed. Perhaps that is just what the Turin authorities intend.

H.E. Gove

Nuclear Structure Research Laboratory, University of Rochester,

Rochester, New York 14627, USA at that point had been reviewed by scores of referees, then I sense that I would probably have considered this whole exercise as degrading or, at best, as a waste of time. In connection with this particular case, Halstead also pointed out that PhD candidates are frequently judged on the basis of their output as measured in terms of the number of pages in their theses. I am more than willing to believe him in this respect and I find that this particular attitude would cause outgrowths of nightmarish proportions if in the future the number of published pages were to play an analogous role.

Peter SenN

Kistlerstrasse 32

8364 Reichenburg, Switzerland

\section{India and China}

SiR-The letter by Upinder Fotadar on "India and China" (Nature 332, 390; 1988) missed almost all points.

First, Fotadar believes that available data in the West about the development of the communist countries are usually inaccurate and insufficient because of the closed-door policy of those countries. His conclusion, therefore, based on the available data, that India leads China in most fields, is incorrect. India leads China in some fields.

Second, it is true that India has the third largest technical manpower in the world. But the advancement of a country depends on the quality of its manpower rather than the quantity, as can be seen in Great Britain, Japan and West Germany.

Third, the scientific achievement of the Eastern-bloc countries cannot be judged solely on the number of research papers published in the Western journals. Statistically speaking, there are more articles in Nature from India than from the Soviet Union. Moreover, Japan, a Western country, produces an enormous number of research papers. But Japanese papers published in journals such as Nature and Science are relatively few because of the lack of manpower to translate them. Is Japan behind India?

Fourth, Fotadar falsely says that China was defeated in the Sino-Vietnamese conflict in 1979. The truth is that China won the war, but it paid the price. That is the nature of war. Moreover, if China had been defeated, how about the wars fought between Russian and Finnish, Chinese and American in Korea, Chinese and Indian in Tibet, Vietnamese and American? Did these wars reflect the backwardness of Russian, American and Indian? JAY J. TU

\section{Program in Advanced}

Ceramic Heat Engine,

Department of Materials Engineering,

Virginia Polytechnic Institute and State University,

Blacksburg, Virginia 24061, USA 